
\title{
25 Research Square \\ Electric Toy Car to Reduce Anxiety Before a Cardiac Catherization: Randomized Controlled Trial
}

Edouard Chambon ( $\nabla$ edouard.chambon3@gmail.com )

Hospital Marie Lannelongue: Centre Chirugical Marie Lannelongue

\section{Emmanuelle Fournier}

Hospital Marie Lannelongue: Centre Chirugical Marie Lannelongue

Maha Tagorti

Hospital Marie Lannelongue: Centre Chirugical Marie Lannelongue

Florence Lecerf

Hospital Marie Lannelongue: Centre Chirugical Marie Lannelongue

\section{Nadera Chaouche}

Hospital Marie Lannelongue: Centre Chirugical Marie Lannelongue

Iolanda lon

Hospital Marie Lannelongue: Centre Chirugical Marie Lannelongue

Mirela Bojan

Hospital Marie Lannelongue: Centre Chirugical Marie Lannelongue

Sarah Cohen

Hospital Marie Lannelongue: Centre Chirugical Marie Lannelongue

Isabelle Van Aerschot

Hospital Marie Lannelongue: Centre Chirugical Marie Lannelongue

\section{Meriem Kara}

Hospital Marie Lannelongue: Centre Chirugical Marie Lannelongue

Clément Batteux

Hospital Marie Lannelongue: Centre Chirugical Marie Lannelongue

Jérome Petit

Hospital Marie Lannelongue: Centre Chirugical Marie Lannelongue

Sébastien Hascoet

Hospital Marie Lannelongue: Centre Chirugical Marie Lannelongue

\section{Research Article}

Keywords: anxiety, electric toy-car, pediatrics, catheterization, congenital heart disease

Posted Date: April 30th, 2021

DOl: https://doi.org/10.21203/rs.3.rs-468450/v1 
License: (c) (i) This work is licensed under a Creative Commons Attribution 4.0 International License. Read Full License 


\section{Abstract}

Anxiety before an invasive intervention is associated in children with persistent psychological disorders. We studied the effect of the transfer to the catheterization room by an electric toy-car on the anxiety of children and their parents before a cardiac catheterization. Forty-eight children with a median age of 5.6 years [4.27.0] were randomized to either riding on an electric car to go to the catheterization laboratory or being transported lying supine on a gurney. Anxiety assessments were performed by a physician blinded to allocation group on the day before the procedure (T0) and at anesthesia induction (T1). The modified Yale score (mYPAS-SF) and visual analog scale for anxiety (VAS-A) were used in the children, and the VAS-A in the parents. The mYPAS-SF, VAS-A-child and the VAS-A-parent scores were significantly higher at T1 than at T0 $(P<0.001, P<0.001$, and $P=0.005$, respectively). The primary outcome (the median mYPAS-SF score at T1) was not significantly different in the two groups when males and females were combined. At $T 1$, the VAS-A-child score, however, was significantly lower in the intervention than the control group (22 versus 55, $P<0.001)$. In the boys, the median mYPAS-SF score at T1 was significantly lower in the intervention group (25.0 versus $51.0, P=0.024)$. No difference was observed in girls. The VAS-A parent score was lower at T1 in the intervention group ( 60 versus $87, P=0.05$ ). Conclusion: Riding to the catheterization laboratory on an electric toy car decreased anxiety at anesthesia induction in boys and also decreased parental anxiety.

Clinical trial Registration: Registration number: ID-RCB: 2019-A00459-48. Date of registration: March 27th 2019.

\section{Summary}

\section{What's Known on This Subject:}

Playful distraction before an invasive procedure by having the child ride on an electric car to the catheterization laboratory has never been studied as a means of managing anxiety.

\section{What's New:}

Ride on electric car significantly alleviated anxiety at anesthesia induction in boys but not girls, it should be used before an invasive procedure in young boys.

\section{Introduction}

Invasive procedures such as surgery or cardiac catheterization generate preoperative anxiety, notably in children, among whom $60 \%$ showed signs of anxiety in one study [1]. Children with congenital heart disease often need open-heart surgery or endo-vascular repair by catheterization, as well as multiple cardiac catheterizations [2]. Preoperative anxiety may manifest itself as verbalization of fear or as agitation, crying, or refusal of care. Negative interpretation bias is common, with the children remembering the pain as more severe than it was [3]. There may be long-term adverse effects such as the onset of new separation anxiety, nightmares, eating disorder or enuresis $[4,5]$. 
The child's strategies for adapting to preoperative anxiety vary with age. Children younger than 5 years of age often have difficulty understanding the explanations given about the procedure and are consequently more likely to develop separation anxiety. However, even young children respond to distraction and reassurance $[4,6,7]$.

Among reported factors related to the child that are associated with worse preoperative anxiety are a shy or anxious temperament, female sex, history of hospitalization, previous traumatic experience with the medical environment, not receiving information, not receiving premedication, and separation from parents $[4,8,9]$. The presence of an anxious parent increases the child's anxiety [10]: a correlation has been demonstrated between the level of anxiety in the parent and that of the child at anesthesia induction $[4,8]$.

Currently, pharmacological agents such as midazolam are used to reduce preoperative anxiety in children. Midazolam has been proven to reduce preoperative anxiety [11, 12], decrease the drug doses required for anesthetic induction, and reduces the risk of separation anxiety and postoperative eating disorders [11]. However, midazolam has a dose-dependent risk of respiratory depression, ataxia, dysphoria, hypotension, and paradoxical reaction with agitation and aggression [12].

Non-pharmacological tools have recently been evaluated as means of decreasing anxiety in children. Distraction with a hand-held video game or electronic tablet decreased preoperative anxiety to a greater extent than did midazolam $[13,14]$. The toy-car is a recent tool whose impact on child anxiety has been little studied [15]. This playful tool involves the child through play, like the other distracting tools currently available, but also makes the child an actor of his own care.

The objective of our randomized controlled trial was to assess the potential anxiety-alleviating effect on the child and parents of having the child drive an electric ride-on car from the ward to the cardiac catheterization laboratory versus being taken on a gurney.

\section{Methods}

\section{Study design}

This trial was approved by the French ethics committee $\left(\mathrm{N}^{\circ} 19.02 .18 .67521\right)$ and was registered prior to patient enrollment in agreement with French legislation (ID-RCB: 2019-A00459-48). Written informed consent was obtained from the parents before inclusion of the each child. This manuscript adheres to the applicable CONSORT guidelines.

Between March 2019 and March 2020, we conducted a single-center, randomized, controlled, single-blind, parallel-group, trial with 1:1 allocation at the Marie Lannelongue Hospital. Consecutive patients between 3 and 10 years of age admitted for cardiac catheterization to assess congenital heart disease were eligible, based on the manufacturer's recommendations on the use of the car. Exclusion criteria were body weight greater than $30 \mathrm{~kg}$ (upper limit for which using the car was approved), cognitive or psychiatric disorder, neurosensory pathology making the child unable to drive the car, lack of understanding of French, and parental refusal. For eligible patients meeting none of these criteria, inclusion in the study was proposed on 
the day before catheterization, after a full explanation of the procedure and study protocol had been given to the parents and children.

\section{Interventions}

The study intervention consisted in having the child drive a toy electric ride-on car from the ward to the catheterization laboratory (Figure 1). On day before the intervention, the physician in charge of each patient randomized to the intervention group provided the child with accurate and playful explanations about the car and how it would be used. In the control group, the children were taken to the catheterization as usual lying supine on a gurney. In both groups, the parents and an orderly accompanied the child. In the intervention group, the orderly had received training about the car and have a remote control that could override the child's actions, to ensure safety.

All children in both groups received standardized preoperative information from a nurse, who used a play kit with figurines to represent the operating room and the course of the operation. No premedication was given in either group. Children in either group who exhibited extreme symptoms of anxiety deemed incompatible with the study protocol were excluded from the study and given vigilant sedation adapted to the level of anxiety.

Once at the catheterization laboratory, the child was separated from the car and parents and given anesthesia promptly. The mode of anesthesia was at the discretion of the anesthesiologist in both groups, a standardized anesthesia protocol was not necessary since we not measure post-procedural status (postemergence delirium for example).

\section{Anxiety assessment}

Anxiety in the child and parents was assessed on the day before the procedure, in the child's room (T0) and on the day of the procedure just before anesthesia induction (T1). The T1 assessment took place after the child was separated from the parents. We used two scales, the short form of the modified Yale Preoperative Anxiety Scale (mYPAS-SF) $[16,17]$ and the Visual Analog Scale for Anxiety (VAS-A). Both scales are validated for assessing anxiety in pediatric patients and adults [18-20].

The mYPAS-SF is validated for children 2 years of age and older [21]. The level of anxiety is proportional to the score. The minimum score is $22 / 100$ and scores above $30 / 100$ reflect anxiety [16]. The scale has four categories illustrating the different forms of expression of anxiety (activity, verbal behavior, expression, and arousal) and each containing four to six items.

The VAS-A can be used for children aged 6 years or older. For younger children, the scale is marked by the parents. The level of anxiety is indicated by placing a mark on a line from 0 to 100 . Scores taken to indicate clinically significant anxiety have ranged across studies from 30 to $50 / 100[18,20]$. We used a cutoff of $30 / 100$. Thus in this trial, we considered a child to be anxious if the mYPAS-SF or the VAS-A-child score 
were above 30.The parents also completed the VAS-A to reflect their own level of anxiety. We defined anxious parents with a VAS-A-parent score above 30.

Thus, anxiety was assessed by three scores (mYPAS-SF, VAS-A-child and VAS-A-parent), by the same blinded investigator, at T0 and T1. The difference between the T1 and T0 scores was taken to reflect anxiety induced by the proximity of the procedure.

\section{Outcomes}

The primary outcome was the median mYPAS-SF score at T1. Secondary outcomes were the median VASA-child score at T1, the median VAS-A-parent score at T1, and the median differences between T1 and T0 $(\triangle T 1-T 0)$ in the mYPAS-SF, VAS-A-child and VAS-A-parent scores.

\section{Randomization}

The randomization sequence was generated by a central computer (STATA $\AA$ Software) in blocks of 4 by a statistician. On the day before catheterization, each patient was enrolled in the study and allocated to one of the two groups by a clinical research associate, with a sealed envelope technique to one of the two groups.

Blinding of the healthcare professionals was not feasible. A physician who had no other role in the study and was unaware of the allocation group conducted the anxiety evaluations and recorded the anonymized results.

\section{Sample size calculation}

The mYPAS-SF, VAS-A-child, and VAS-A-parent scores were considered to indicate anxiety if greater than 30/100. Based on a previous comparable study, we hypothesized that the median T1 mYPAS-SF score would be 60/100 in the control group and 45/100 in the intervention group[15]. With a standard deviation of 15 , an alpha risk of 0.05 , and a beta risk of $0.10,22$ patients were required in each group to detect a statistically significant difference in the median mYPAS-SF score at T1 (primary outcome) between the two groups.

\section{Statistical Analysis}

The statistical analysis was carried out using the per-protocol approach. Non-normal and ordinal values were described as median [interquartile range]. Quantitative non-normal values, such as the mYPAS-SF score, were compared using the non-parametric Mann-Whitney test. Qualitative variables were described as percentages and compared using Fisher's exact test. Quantitative normally distributed variables were compared using the Wilcoxon rank test. $P$ values $<0.05$ were considered significant. 


\section{Results}

\section{Flow chart and study population}

As seen in Fig. 2 Flow chart, we identified 63 patients meeting our inclusion criteria between March 2019 and March 2020. Fifteen children were excluded before randomization for the following reasons: delayed psychomotor development (eight children), deafness (one child), and weight over $30 \mathrm{~kg}$ (six children). A total of 48 patients were randomized. Four children were excluded after randomization: one child because of parental refusal to continue the study and three children requiring sedation before transfer to the catheterization laboratory (one child in the intervention group and two children in the control group). Among them, 44 were finally analyzed in the study, 22 in each group. Table 1 reports their main features. 
Table 1

Main features of the study patients

\begin{tabular}{|c|c|c|}
\hline & Intervention & Control \\
\hline Patients, n (\%) & $22(50)$ & $22(50)$ \\
\hline Male, n (\%) & $12(54.5)$ & $12(54.5)$ \\
\hline Age (years) & $4.7[4.0-5.8]$ & $6.3[5.3-7.4]$ \\
\hline Weight (Kg) & $19.2[15.2-22.0]$ & $22.0[18.4-24.9]$ \\
\hline \multicolumn{3}{|l|}{ Heart disease ${ }^{a}, \mathrm{n}(\%)$} \\
\hline Simple heart disease & $14(63.6)$ & $12(54.5)$ \\
\hline Complex heart disease & $5(22.7)$ & $5(22.7)$ \\
\hline Isolated heart rhythm disorder & $3(13.6)$ & $5(22.7)$ \\
\hline Surgery or catheterization history, n (\%) & $8(36.4)$ & $5(22.7)$ \\
\hline Position at catheterization ${ }^{\mathrm{b}}$ & $3.0[1.0-3.0]$ & $3.5[2.0-5.0]$ \\
\hline \multicolumn{3}{|l|}{ Catheterization type, n (\%) } \\
\hline Diagnostic & $3(13.6)$ & $5(22.7)$ \\
\hline Rhythmologic & $4(18.2)$ & $4(18.2)$ \\
\hline Interventional & $15(68.2)$ & $13(59.1)$ \\
\hline \multicolumn{3}{|l|}{ Type of anesthesia, $n(\%)$} \\
\hline General anesthesia & $8(36.4)$ & $14(63.6)$ \\
\hline Sedation with spontaneous ventilation & $14(63.6)$ & $8(36.4)$ \\
\hline \multicolumn{3}{|c|}{$\begin{array}{l}\text { aAccording to the classification of the rare diseases M3C network for complex congenital heart diseas } \\
\text { [37]. } 26(59.0 \%) \text { patients had a simple congenital heart disease (patent ductus arteriosus, atrial septal } \\
\text { defect, ventricular septal defect, or pulmonary valvular stenosis) and } 10(22.7 \%) \text { patients had a } \\
\text { complex heart disease (tetralogy of Fallot; single ventricle; common arterial trunk; double-issue right } \\
\text { ventricle; and combined transposition of the great arteries, ventricular septal defect, and pulmonary } \\
\text { stenosis). Eight patients }(18.2 \%) \text { had a structurally healthy heart and were admitted for ablative thera } \\
\text { by catheterization (electrophysiological study) to treat tachycardia. }\end{array}$} \\
\hline
\end{tabular}

\section{Anxiety in the children}

Across both groups at T0, 38.6\% of the children met our definition for anxiety (mYPAS-SF or VAS-A-child score above 30 ): $36.4 \%$ in the intervention group and $40.9 \%$ in the control group, without significant 
difference between groups. At T1, there was $81.8 \%$ of anxious children $(72.7 \%$ in the intervention group and $90.9 \%$ in the control group), again with no significant between-group difference.

Table 2 lists the child anxiety scores at T0 and T1. The median mYPAS-SF score at T1 (primary outcome) was not significantly different between the two groups. At T1, the VAS-A-child score, however, was significantly lower in the intervention than the control group.

Table 2

Values of the mYPAS-SF, VAS-A in children, and VAS-A in parents on the day before the procedure (T0) and just before anesthesia induction (T1)

\begin{tabular}{|c|c|c|c|c|c|}
\hline & \multicolumn{2}{|c|}{ Intervention } & \multicolumn{2}{|c|}{ Control } & $P$ val \\
\hline & \multicolumn{2}{|l|}{$n=22$} & \multicolumn{2}{|l|}{$\mathrm{n}=22$} & \\
\hline \multicolumn{6}{|l|}{ mYPAS-SF score } \\
\hline T0 & 22.9 & [22.9-22.9] & 22.9 & [22.9-32.9] & 0.36 \\
\hline $\mathrm{T} 1$ & 33.3 & [22.9-62.4] & 52.0 & [29.2-62.5] & 0.25 \\
\hline$\triangle \mathrm{T} 1-\mathrm{T} 0$ & 7.2 & [0.0-29.6] & 14.6 & [6.2-33.9] & 0.19 \\
\hline$P$ value $^{\mathrm{b}}$ & 0.003 & & $<0.00^{-}$ & & \\
\hline
\end{tabular}

VAS-A parent score

\begin{tabular}{llllll} 
T0 & 54 & {$[45-65]$} & 44 & {$[22-64]$} & 0.34 \\
\hline T1 & 60 & {$[30-80]$} & 87 & {$[54-100]$} & 0.05 \\
$\triangle \triangle$ T1 - T0 & 13 & {$[-9-20]$} & 30 & {$[7-49]$} & 0.026 \\
$P$ value $^{\text {b }}$ & 0.25 & & $<0.001$ & &
\end{tabular}

\section{VAS-A child score}

\begin{tabular}{llllll} 
T0 & 10 & {$[0-32]$} & 16 & {$[0-36]$} & 0.69 \\
T1 & 22 & {$[0-50]$} & 55 & {$[37-70]$} & $<0.001$ \\
$\triangle \mathrm{T} 1-\mathrm{T0}$ & 10 & {$[0-40]$} & 35 & {$[15-55]$} & 0.51 \\
\hline value $^{\mathrm{b}}$ & 0.05 & & $<0.001$ & &
\end{tabular}

$\mathrm{T} 0$, day before the procedure; $\mathrm{T} 1$, just before anesthesia induction, after separation from the parents; $\Delta \mathrm{T} 1-\mathrm{T} 0$, increase in anxiety between the two time points

${ }^{a}$ for the comparison of the two groups

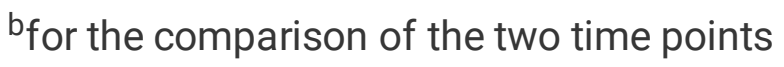

The T1 scores were significantly higher than the T0 scores in both groups, with no significant difference. 
At T0, $72.7 \%$ of parents in both groups had anxiety according to our definition $(81.8 \%$ in the intervention group and $63.6 \%$ in the control group, $P=0.31)$. At $\mathrm{T} 1,77.2 \%$ of all parents reported anxiety $(68.2 \%$ in the intervention group and $86.4 \%$ in the control group, $P=0.28$ ). The number of patients with anxiety was not significantly higher at T1 than at T0. However, the increase in the VAS-A-parent score at T1 compared to T0 was significant in the control group but not in the intervention group.

Separate evaluation of male and female patients (Table 3) 
Table 3

Separate evaluation of female and male patients

\section{MALES \\ FEMALES}

$\begin{array}{llllll}\text { Intervention } & \text { Control } & \begin{array}{l}P \\ \text { value }^{\mathbf{a}}\end{array} & \text { Intervention } & \text { Control } & \begin{array}{l}P \\ \text { value }^{\mathbf{a}}\end{array} \\ \mathrm{n}=12 & \mathrm{n}=12 & & \mathrm{n}=10 & \mathrm{n}=10 & \end{array}$

\section{mYPAS-}

SF score

\begin{tabular}{|c|c|c|c|c|c|c|c|c|c|c|}
\hline T0 & 22.9 & $\begin{array}{l}{[22.9-} \\
22.9]\end{array}$ & 22.9 & $\begin{array}{l}{[22.9-} \\
26.6]\end{array}$ & 0.32 & 22.9 & $\begin{array}{l}{[22.9-} \\
30.7]\end{array}$ & 25.0 & $\begin{array}{l}{[22.9-} \\
33.9]\end{array}$ & 0.80 \\
\hline T1 & 25.0 & $\begin{array}{l}{[22.9-} \\
33.3]\end{array}$ & 51.0 & $\begin{array}{l}{[27.6-} \\
66.7]\end{array}$ & 0.024 & 68.6 & $\begin{array}{l}{[36.4-} \\
77.5]\end{array}$ & 54.2 & $\begin{array}{l}{[30.8-} \\
62.0]\end{array}$ & 0.25 \\
\hline$\underset{\mathrm{TO}}{\triangle \mathrm{T} 1-}$ & 0.0 & $\begin{array}{l}{[0.0-} \\
10.3]\end{array}$ & 14.6 & $\begin{array}{l}{[4.7-} \\
32.2]\end{array}$ & 0.024 & 38.5 & $\begin{array}{l}{[2.6-} \\
54.6]\end{array}$ & 15.7 & $\begin{array}{l}{[7.3-} \\
33.9]\end{array}$ & 0.36 \\
\hline $\begin{array}{l}P \\
\text { value }^{\mathrm{b}}\end{array}$ & 0.06 & & $\begin{array}{l}< \\
0.001\end{array}$ & & & 0.02 & & 0.01 & & \\
\hline
\end{tabular}

\section{VAS-A \\ parent \\ score}

\begin{tabular}{|c|c|c|c|c|c|c|c|c|c|c|}
\hline T0 & 54 & $\begin{array}{l}{[44-} \\
62]\end{array}$ & 43 & $\begin{array}{l}{[17-} \\
65]\end{array}$ & 0.45 & 57 & $\begin{array}{l}{[47-} \\
65]\end{array}$ & 44 & [22-59] & 0.50 \\
\hline T1 & 65 & $\begin{array}{l}{[41-} \\
75]\end{array}$ & 79 & $\begin{array}{l}{[49-} \\
100]\end{array}$ & 0.24 & 50 & $\begin{array}{l}{[23-} \\
80]\end{array}$ & 89 & [75-94] & 0.15 \\
\hline$\frac{\Delta \mathrm{T} 0}{\mathrm{~T} 1}-$ & 15 & $\begin{array}{l}{[-2-} \\
23]\end{array}$ & 30 & $\begin{array}{l}{[11-} \\
46]\end{array}$ & 0.11 & 7 & $\begin{array}{l}{[-30-} \\
16]\end{array}$ & 30 & [7-63] & 0.11 \\
\hline $\begin{array}{l}P \\
\text { value }^{\mathrm{b}}\end{array}$ & 0.08 & & $\begin{array}{l}< \\
0.0\end{array}$ & & & 1 & & 0.02 & & \\
\hline
\end{tabular}

\section{VAS-A}

child

score

\begin{tabular}{|c|c|c|c|c|c|c|c|c|c|c|}
\hline T0 & 5 & {$[0-17]$} & 0 & [0-28] & 0.80 & 17 & {$[3-40]$} & 25 & [14-36] & 0.62 \\
\hline T1 & 5 & [0-19] & 55 & $\begin{array}{l}{[40-} \\
79]\end{array}$ & $\begin{array}{l}< \\
0.001\end{array}$ & 50 & $\begin{array}{l}{[40-} \\
85]\end{array}$ & 55 & [34-64] & 0.80 \\
\hline$\stackrel{\triangle \mathrm{T} 1}{\mathrm{~T} 1}$ & 0 & $\begin{array}{l}{[-11-} \\
10]\end{array}$ & 41 & $\begin{array}{l}{[33-} \\
59]\end{array}$ & $<_{0.001}$ & 40 & $\begin{array}{l}{[22-} \\
48]\end{array}$ & 22 & {$[-2-49]$} & 0.40 \\
\hline
\end{tabular}

${ }^{a}$ for the comparison of the two groups

${ }^{b}$ for the comparison of the two time points 


\begin{tabular}{|c|c|c|c|c|}
\hline \multicolumn{3}{|c|}{ MALES } & \multicolumn{2}{|c|}{ FEMALES } \\
\hline $\begin{array}{l}P \\
\text { value }\end{array}$ & 0.91 & $\begin{array}{l}<.001 \\
0.01\end{array}$ & 0.01 & 0.11 \\
\hline \multicolumn{5}{|c|}{${ }^{\text {a }}$ for the comparison of the two groups } \\
\hline
\end{tabular}

Among boys, the median mYPAS-SF score at T1 (primary outcome) was significantly lower in the intervention group than in the control group. The boys median VAS-A-child score was also significantly lower in the intervention group. Furthermore, for boys, the increases in both scores from T0 to T1 were significant in the control group but not in the intervention group. The increase in the male VAS-A-parent score between T0 and T1 was significant in the control group but not in the intervention group. There was no significant difference in the VAS-A-parent scores at T0 and T1 between the two groups.

Among girls, the median mYPAS-SF score at T1 (primary outcome) was not significantly different between the two groups. Neither was the girls median VAS-A-child score at T1 significantly different between groups. The increase in the mYPAS-SF score from T0 to T1 was significant in both groups. The increase in the girls VAS-A-child score was significant in the intervention group but not in the control group. There was no significant difference in the female VAS-A-parent score at T0 and T1 between the two groups. However, the increase in the VAS-A-parent score from T0 to T1 was significant in the female control group but not in the intervention group.

\section{Discussion}

In this randomized controlled trial assessing the effect on pre-procedural anxiety of a non-pharmacological intervention based on distraction and active participation, the median mYPAS-SF score at T1 was not significantly different in the two groups when males and females were combined. In the boys, however, the median mYPAS-SF score at T1 was significantly lower in the intervention than in the control group. Furthermore, the boys, but not the girls, had a significantly smaller increase from T0 to T1 on both the mYPAS-SF and VAS-A-child scores. Thus, our intervention was effective in the boys but not in the girls. The VAS-A-parent score increased significantly less from T0 to T1 in the intervention group.

Overall, $38.6 \%$ of children met our definition of anxiety on the day before the procedure compared to $81.8 \%$ at the time of transfer to the catheterization laboratory. This very high prevalence of anxiety is of concern. However, it should be noted that we chose a low cut-off of 30/100 on the VAS-A scale to define anxiety in both children and parents. Also, our patients had congenital heart defects that often require multiple invasive investigations and corrective procedures, which feed a constant level of anxiety in the entire family. Thus, parental anxiety was also very common in our study, with nearly three-fourths of parents being anxious at both time points. The number of parents with anxiety at T1 in our study was lower compared to TO in the intervention group and higher in the control group. Thus, the toy car seems to have had a distractive effect on the parents also. Alleviating parental anxiety is important, as anxiety in the 
parents increases stress in the child $[7,9,22]$. Therapeutic education and adapted parental information before heart surgery, for example, has been proven effective in decreasing parental anxiety [23].

A randomized controlled trial from China that used the same assessment tools as we did enrolled children aged 2 to 5 years undergoing their first corrective surgery for congenital heart disease [15]. The children in the intervention group were taken to the operating room in a manual toy car pushed by an orderly, instead of being transported supine on a gurney. The anxiety scores in the children were significantly lower in the car group than in the gurney group. This study also had a midazolam arm, in which the scores were comparable to those in the car arm. The initial anxiety scores (TO) were similar to those in our study. However, the scores at induction ( $\mathrm{T} 1$ ) were slightly lower in our study, perhaps due to our use of figurines to explain the procedure to the children, to the type of intervention (open-heart surgery versus cardiac catheterization), and/or to the younger patient age in the Chinese study.

Other methods of distraction designed to alleviate preoperative anxiety have been used. A metaanalysis showed that a preoperative clown intervention alleviated anxiety in both children and parents [24]. Video games and interactive games have also been evaluated for reducing stress and pain levels [23] and appear to be the most effective distractors [25]. Hypnosis in the operating room in older children aged 10-18 years showed no effect on anxiety or postoperative pain levels [26]. Exposure to a virtual reality experience of the operating room also failed to reduce anxiety or pain in children 4 to 12 years of age [27]. In contrast, storytelling and coloring was not inferior to midazolam in alleviating children's preoperative anxiety [28].

The importance of age-appropriate information for decreasing preoperative anxiety has been demonstrated by studies in which animated stories, with explanations of feelings of fear, pain, and anxiety, decreased preoperative anxiety levels $[29,30]$. The use of audiovisual information tools has also been shown to alleviate preoperative anxiety in children [31, 32]. In another randomized trial, distraction by using an interactive tablet was more effective than midazolam sedation in alleviating anxiety at induction, decreasing emergence delirium, and allowing earlier extubation, and earlier hospital discharge [13]. Conversely, in children aged 9 to 18 years scheduled for thoracic surgery, all of whom received preoperative information by a nurse, adding information by a psychologist was effective only in those children with a low level of trait anxiety [33]. Therapeutic play before surgery, e.g., using a doll to explain the procedure has had variable effects depending on the study population, mode of play, and type of surgery (outpatient or conventional, and depending on the organ operated on) [34]. However, a 2019 study in children aged 6 to 12 years scheduled for heart surgery found that preoperative play education was effective in diminishing postoperative anxiety in both the children and their mothers [35].

Our study has several limitations. First, we did not choose a gender-neutral or two gender-specific distracting activities. In a 2020 meta-analysis that looked at 113 effect sizes from 75 studies of toy preference, boys preferred vehicles and this effect was large and statistically significant [36]. This explains the significantly lower median mYPAS-SF score at T1 in the intervention group in the boys but not in the girls in our study. Second, we did not collect data on the anesthetic drug doses, quality of awakening, or postoperative anxiety. Third, combination of the car ride with other activities before the transfer to the catheterization room might have produced greater effects on anxiety. Finally, we did not assess the children

Page $13 / 20$ 
or parents for trait anxiety. Such an assessment might be useful to identify children and parents who are at high risk for anxiety and therefore require special efforts to lessen preoperative and postoperative anxiety.

\section{Conclusion}

Playful distraction by means of having the child ride on an electric toy car to go to the operating room was effective in lessening preoperative anxiety at the time of induction in boys but not in girls. Further studies are warranted using gender-specific and/or gender-neutral toys or activities for a longer period before cardiac catheterization.

\section{Abbreviations}

mYPAS-SF modified YALE Preoperative Anxiety Scale Short Form

DT1-T0 Subtraction between T1 and T0 for the VAS-A and the mYPAS-SF scores

VAS-A Visual Analog Scale for anxiety

VAS-A-child VAS of anxiety of the child in hetero-evaluation by his parents

VAS-A-parent VAS of parental anxiety self-assessment

\section{Declarations}

Funding:

None

\section{Conflict of interest disclosure:}

The authors have no conflicts of interest relevant to this article to disclose.

\section{Availability of data and material:}

Deidentified individual participant data will not be made available.

\section{Code availability:}

Not applicable.

\section{Authors' contribution:}


Dr Chambon Dr Fournier, Dr Tagorti, Dr Hascoet conceptualized and designed the study, drafted the initial manuscript, carried out the initial analyses, and revised the manuscript. Mrs Lecerf and Mrs Chaouche designed the study and critically reviewed the manuscript. Dr Ion, Dr Bojan, Dr Cohen, Dr Van-Aerschot, Dr Mostefa-Kara, Dr Batteux and Dr Petit collected data and critically reviewed the manuscript for important intellectual content. All authors approved the final manuscript as submitted and agree to be accountable for all aspects of the work.

\section{Ethics approval:}

This trial was approved by the French ethics committee $\left(\mathrm{N}^{\circ} 19.02 .18 .67521\right)$

\section{Consent to participate and for publication:}

freely-given, informed consent to participate and for publication was obtained from parents of participants.

\section{Acknowledgments:}

We thank the town of Tancarville, which donated the electric toy car. We are also grateful to the nurses and orderlies who participated in the study.

\section{References}

1. Sola C, Lefauconnier A, Bringuier S, et al (2017) Childhood preoperative anxiolysis: Is sedation and distraction better than either alone? A prospective randomized study. Pediatr Anesth 27:827-834. https://doi.org/10.1111/pan.13180

2. Butler SC, Sadhwani A, Stopp C, et al (2019) Neurodevelopmental assessment of infants with congenital heart disease in the early postoperative period. Congenit Heart Dis 14:236-245. https://doi.org/10.1111/chd.12686

3. Noel M, Rosenbloom B, Pavlova M, et al (2019) Remembering the pain of surgery 1 year later: a longitudinal examination of anxiety in children's pain memory development. Pain 160:1729-1739. https://doi.org/10.1097/j.pain.0000000000001582

4. Kain Z, Mayes L, O'Connor T (1996) Preoperative anxiety in children predictors and outcomes. Arch Pediatr Adolesc Med 150:. https://doi.org/10.1001/archpedi.1997.02170430102029

5. Kain ZN, Wang SM, Mayes LC, et al (1999) Distress During the Induction of Anesthesia and Postoperative Behavioral Outcomes. Anesth Analg

6. McGraw T (1994) Preparing children for the operating room: psychological issues. Can J Anaesth 41:1094-1103. https://doi.org/10.1007/BF03015661

7. Vetter TR (1993) The epidemiology and selective identification of children at risk for preoperative anxiety reactions. Anesth Analg 77:. https://doi.org/10.1213/00000539-199307000-00019 
8. Kain ZN, Mayes LC, Weisman SJ, Hofstadter MB (2000) Social adaptability, cognitive abilities, and other predictors for children's reactions to surgery. J Clin Anesth 12:549-554.

https://doi.org/10.1016/S0952-8180(00)00214-2

9. Charana A, Tripsianis G, Matziou V, et al (2018) Preoperative anxiety in greek children and their parents when presenting for routine surgery. Anesthesiol Res Pract 2018:1-6.

https://doi.org/10.1155/2018/5135203

10. Kain ZN, Mayes LC, Caldwell-Andrews AA, et al (2006) Predicting which children benefit most from parental presence during induction of anesthesia. Pediatr Anesth 16:627-634.

https://doi.org/10.1111/j.1460-9592.2006.01843.x

11. Watson AT, Visram A (2003) Children's preoperative anxiety and postoperative behaviour. Pediatr Anesth 13:188-204. https://doi.org/10.1046/j.1460-9592.2003.00848.x

12. Manso MA, Guittet C, Vandenhende F, Granier L (2019) Efficacy of oral midazolam for minimal and moderate sedation in pediatric patients: A systematic review. Pediatr Anesth 29:1094-1106. https://doi.org/10.1111/pan.13747

13. Stewart B, Cazzell MA, Pearcy T (2018) Single-blinded randomized controlled study on use of interactive distraction versus oral midazolam to reduce pediatric preoperative anxiety, emergence delirium, and postanesthesia length of stay. J Perianesth Nurs. https://doi.org/10.1016/j.jopan.2018.08.004

14. Patel A, Schieble T, Davidson $M$, et al (2006) Distraction with a hand-held video game reduces pediatric preoperative anxiety. Pediatr Anesth 16:1019-1027. https://doi.org/10.1111/j.14609592.2006.01914.x

15. Liu PP, Sun Y, Wu C, et al (2018) The effectiveness of transport in a toy car for reducing preoperative anxiety in preschool children: a randomised controlled prospective trial. Br J Anaesth 121:438-444. https://doi.org/10.1016/j.bja.2018.02.067

16. Jenkins BN, Fortier MA, Kaplan SH, et al (2014) Development of a short version of the modified Yale preoperative anxiety scale. Anesth Analg 119:643-650.

https://doi.org/10.1213/ANE.0000000000000350

17. Kain ZN, Mayes LC, Cicchetti V, et al (1997) The Yale preoperative anxiety scale: how does it compare with a "gold standard"? Anesth Analg

18. Berghmans JM, Poley MJ, van der Ende J, et al (2017) A visual analog scale to assess anxiety in children during anesthesia induction (VAS-I): Results supporting its validity in a sample of day care surgery patients. Pediatr Anesth 27:955-961. https://doi.org/10.1111/pan.13206

19. Bringuier S, Dadure C, Raux O, et al (2009) The perioperative validity of the visual analog anxiety scale in children: a discriminant and useful instrument in routine clinical practice to optimize postoperative pain management. Anesth Analg 109:737-744. https://doi.org/10.1213/ane.0b013e3181af00e4

20. Facco E, Stellini E, Bacci C, et al (2013) Validation of visual analogue scale for anxiety (VAS-A) in preanesthesia evaluation. Minerva Anestesiol 79: 
21. Kühlmann AYR, Lahdo N, Staals LM, van Dijk M (2018) What are the validity and reliability of the modified Yale preoperative anxiety scale-short form in children less than 2 years old? Pediatr Anesth. https://doi.org/10.1111/pan.13536

22. Werner O, El Louali F, Fouilloux V, et al (2019) Parental anxiety before invasive cardiac procedure in children with congenital heart disease: Contributing factors and consequences. Congenit Heart Dis 14:778-784. https://doi.org/10.1111/chd.12777

23. Kumar A, Das S, Chauhan S, et al (2019) Perioperative anxiety and stress in children undergoing congenital cardiac surgery and their parents: Effect of brief intervention-A randomized control trial. J Cardiothorac Vasc Anesth 33:1244-1250. https://doi.org/10.1053/j.jvca.2018.08.187

24. Zhang Y, Yang Y, Lau WY, et al (2017) Effectiveness of pre-operative clown intervention on psychological distress: A systematic review and meta-analysis: Meta-analysis of clown intervention. $J$ Paediatr Child Health 53:237-245. https://doi.org/10.1111/jpc.13369

25. Chow CHT, Van Lieshout RJ, Schmidt LA, et al (2016) Systematic review: Audiovisual interventions for reducing preoperative anxiety in children undergoing elective surgery. J Pediatr Psychol 41:182-203. https://doi.org/10.1093/jpepsy/jsv094

26. Duparc-Alegria N, Tiberghien $\mathrm{K}$, Abdoul $\mathrm{H}$, et al (2018) Assessment of a short hypnosis in a paediatric operating room in reducing postoperative pain and anxiety: A randomised study. J Clin Nurs 27:86-91. https://doi.org/10.1111/jocn.13848

27. Eijlers R, Dierckx B, Staals LM, et al (2019) Virtual reality exposure before elective day care surgery to reduce anxiety and pain in children: A randomised controlled trial. Eur $\mathrm{J}$ Anaesthesiol 36:728-737. https://doi.org/10.1097/EJA.0000000000001059

28. Al-Yateem N, Brenner M, Shorrab AA, Docherty C (2016) Play distraction versus pharmacological treatment to reduce anxiety levels in children undergoing day surgery: A randomized controlled noninferiority trial. Child Care Health Dev 42:572-581. https://doi.org/10.1111/cch.12343

29. Shaheen A, Nassar O, Khalaf I, et al (2018) The effectiveness of age-appropriate pre-operative information session on the anxiety level of school-age children undergoing elective surgery in Jordan. Int J Nurs Pract 24:e12634. https://doi.org/10.1111/ijn.12634

30. Sekhavatpour Z, Khanjani N, Reyhani T, et al (2019) The effect of storytelling on anxiety and behavioral disorders in children undergoing surgery: a randomized controlled trial. Pediatr Health Med Ther Volume 10:61-68. https://doi.org/10.2147/PHMT.S201653

31. Dai Y, Livesley J (2018) A mixed-method systematic review of the effectiveness and acceptability of preoperative psychological preparation programmes to reduce paediatric preoperative anxiety in elective surgery. J Adv Nurs 74:2022-2037. https://doi.org/10.1111/jan.13713

32. Hatipoglu Z, Gulec E, Lafli D, Ozcengiz D (2018) Effects of auditory and audiovisual presentations on anxiety and behavioral changes in children undergoing elective surgery. Niger $\mathrm{J}$ Clin Pract 21:788. https://doi.org/10.4103/njcp.njcp_227_17

33. Tomaszek L, Cepuch G, Fenikowski D (2018) Influence of preoperative information support on anxiety, pain and satisfaction with postoperative analgesia in children and adolescents after thoracic surgery: a randomized double blind study. Biomed Pap. https://doi.org/10.5507/bp.2018.060 
34. He H-G, Zhu L, Chan SWC, et al (2015) The effectiveness of therapeutic play intervention in reducing perioperative anxiety, negative behaviors, and postoperative pain in children undergoing elective surgery: A systematic review. Pain Manag Nurs 16:425-439.

https://doi.org/10.1016/j.pmn.2014.08.011

35. Coşkuntürk AE, Gözen D (2018) The effect of interactive therapeutic play education program on anxiety levels of children undergoing cardiac surgery and their mothers. J Perianesth Nurs 33:781789. https://doi.org/10.1016/j.jopan.2017.07.009

36. Davis JTM How large are gender differences in toy preferences? A systematic review and metaanalysis of toy preference research. Arch Sex Behav 22

37. M3C Network Classification of complex congenital heart disease

\section{Figures}

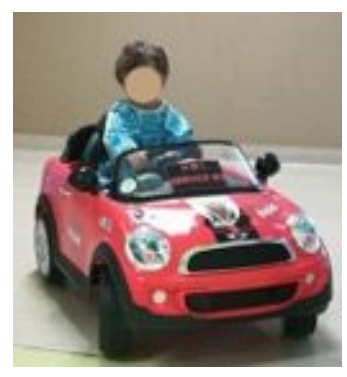

Figure 1

The electric ride-on toy car 


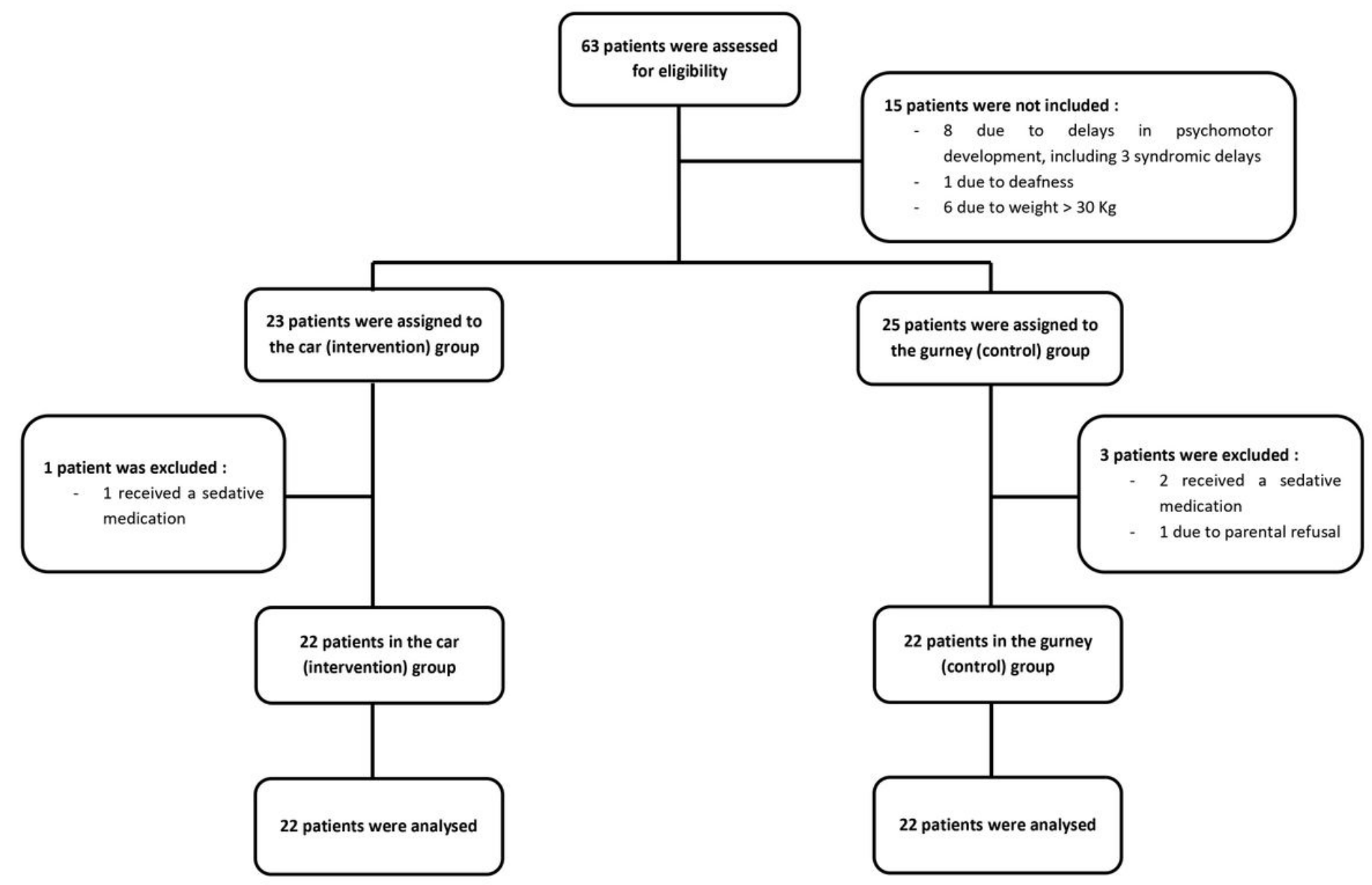

\section{Figure 2}

The patient flow diagram (created with Word) 


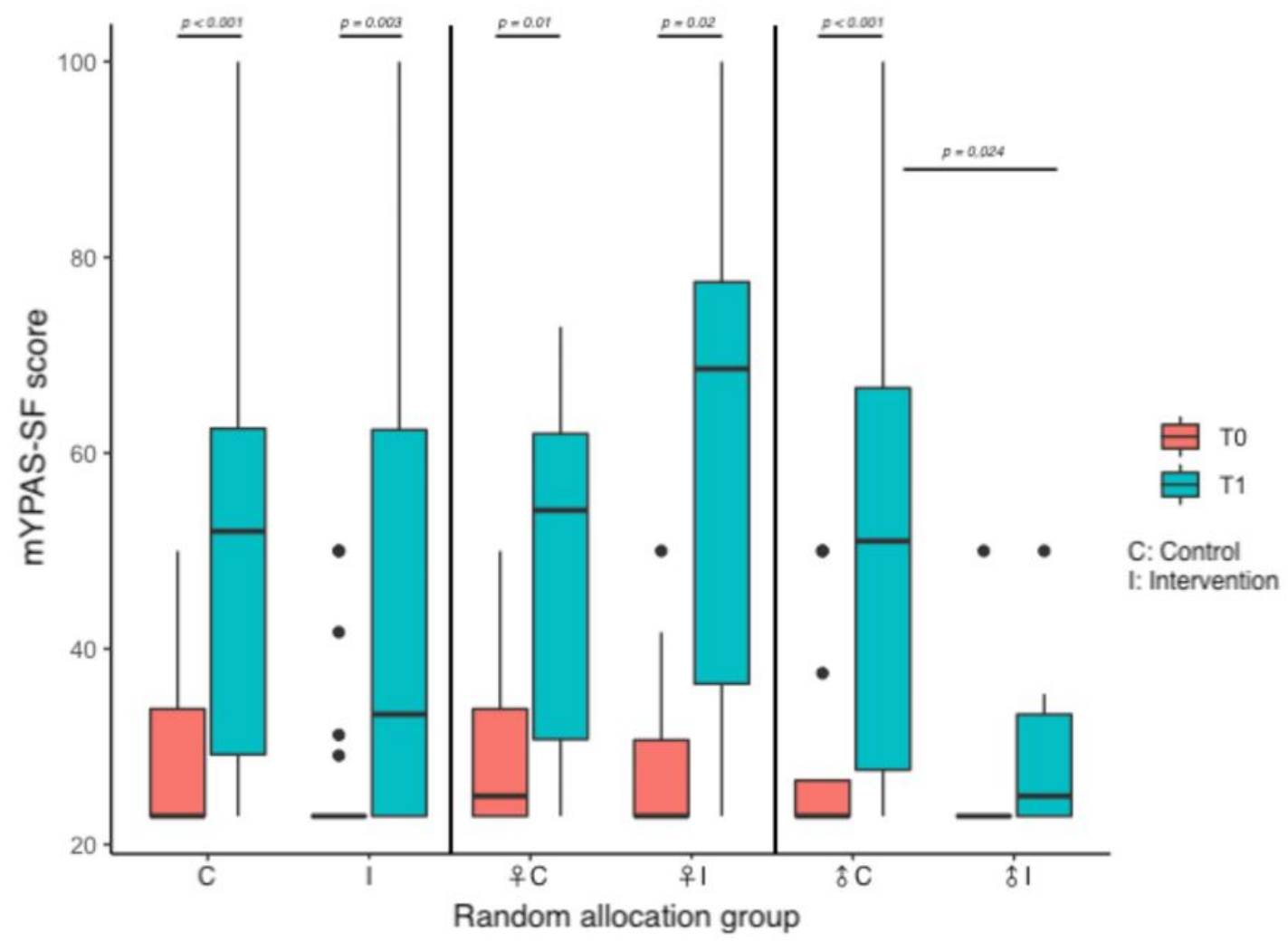

Figure 3

Changes in the mYPAS-SF score in the two groups, overall and for boys and girls separately (created with Rstudio). 